\title{
Family Avoidance of Communication about Cancer: A Dyadic Examination
}

\section{Dong Wook Shin, MD, DrPH, MBA ${ }^{1,2}$ \\ Jooyeon Shin, $\mathrm{PhD}^{3}$ \\ So Young Kim, MD, $\mathrm{PhD}{ }^{4}$ \\ Hyung-Kook Yang, MD, MPH ${ }^{4}$ \\ Juhee Cho, MA, PhD 5,6,7 \\ Jung Ho Youm, MD, PhD ${ }^{8}$ \\ Gyu Seog Choi, MD, PhD 9 \\ Nam Soo Hong, MD ${ }^{10}$ \\ BeLong Cho, MD, MPH, PhD',2 \\ Jong-Hyock Park , MD, MPH, PhD ${ }^{4,11}$}

${ }^{1}$ Department of Family Medicine and

Health Promotion Center,

Seoul National University Hospital, Seoul,

${ }^{2}$ Cancer Survivorship Clinic,

Seoul National University Cancer Hospital,

Seoul, ${ }^{3}$ Department of Counseling Psychology,

Hanyang Cyber University, Seoul,

${ }^{4}$ Cancer Policy Branch,

National Cancer Control Institute,

National Cancer Center, Goyang,

${ }^{5}$ Department of Health Sciences and Technology,

SAHIST and School of Medicine,

Sungkyunkwan University, Seoul, Korea,

Departments of ${ }^{6}$ Health and ${ }^{7}$ Epidemiology,

Behavior, and Society, Johns Hopkins Bloomberg

School of Public Health, Baltimore, MD, USA,

${ }^{8}$ Department of Preventive Medicine and

Public Health, Chonbuk National University

School of Medicine, Cheonju,

${ }^{9}$ Colorectal Cancer Center,

Kyungpook National University Medical Center, Kyungpook National University

School of Medicine, Daegu,

${ }^{10}$ Department of Preventive Medicine,

Kyungpook National University

School of Medicine, Daegu,

${ }^{11}$ College of Medicine/Graduate

School of Health Science Business Convergence,

Chungbuk National University, Cheongju, Korea

Correspondence : Jong-Hyock Park, MD, MPH, PhD College of Medicine/Graduate

School of Health Science Business Convergence,

Chungbuk National University, 1 Chungdae-ro,

Seowon-gu, Cheongju 28644, Korea

Tel: $82-43-261-2873$

Fax: 82-43-261-3459

E-mail: jonghyock@gmail.com

Received October 6, 2014

Accepted January 15, 2014

Published Online March 13, 2015

\section{Purpose}

This study aimed to examine the following questions: to what extent do patients and caregivers perceive their family members to be avoidant of communication regarding patient's cancer, and to what extent do these perceptions interrelate; and how do such perceptions influence their own and each other's communication behaviors, communication outcome, mental health, and quality of life.

\section{Materials and Methods}

A national survey was performed with 990 patient-caregiver dyads (participation rate, 76.2\%). To examine the dyadic interaction, we developed linked patient and family member questionnaires, including the Family Avoidance of Communication about Cancer (FACC) scale.

\section{Results}

The mean scores (standard deviations) of patient- and caregiver-perceived FACC were low at 10.9 (15.5) and $15.5(17.5)$, respectively $(p<0.001)$, and concordance was low, a well (Spearman's rho, 0.23). Patient-perceived FACC was associated with lower levels of disclosure and behaviors of holding back communication, as well as lower levels of mental health outcome and quality of life. The same was true for caregivers (all $p<0.05$ ). Patient-perceived FACC was associated with caregiver holding back, caregiver's depression level, and caregiver quality of life (all $p<0.05$ ). Both patient- and caregiver-perceived FACC were independently associated with communication difficulty within the family.

\section{Conclusion}

Future research would benefit from the measurement of FACC from both patients and caregivers, and promote family intervention to enhance openness to communication, which would be helpful for improving mental health and quality of life for both patients and caregivers. 


\section{Introduction}

Cancer has become a chronic disease characterized by long-term management and ambulatory care. Therefore, constant interaction between patients and caregiver is becoming increasingly important, and the role of the caregiver is becoming crucial for optimal cancer care. Strong communication between patient and caregiver is vital for the success of this relationship; however, the role of communication in patient outcomes is only now beginning to be recognized [1].

Previous studies have found that patients and caregivers often do not communicate openly about cancer. Namely, both parties tend to hide concerns and fears from the other [2-7], even if both consider the relationship to be highly satisfying [5]. Both patients and caregivers want to protect each other from psychological distress, and many caregivers believe that it is harmful for patients to discuss the negative aspects of their illness [5,8-10]. Furthermore, some caregivers avoid such discussion due to their own fear about cancer [11].

Prior studies have consistently demonstrated that higher levels of open communication between patients and caregivers show an association with positive psychological outcomes, whereas avoidance of family communication may have a negative impact on both parties [2,9]. Such studies investigated the openness of communication regarding cancer, measured by either the patient or caregiver self-reported experience or perception of experience $[2,9,10]$. Given that a direct observation of actual communication avoidance between patients and caregivers would not be feasible, selfreport of one's own perception of communication avoidance may offer some information about actual communication $[12,13]$. In addition, it is one's own perception of communication that may influence future behaviors in cancer management and may ultimately influence health outcomes. However, family communication as perceived by patients may differ from patient communication as perceived by family members. Thus far, researchers have not granted systematic attention to communication avoidance between patients and caregivers [12,14]. Moreover, mutual influence of communication avoidance as perceived by patients and caregivers on each other's outcome has been rarely examined [15].

In addition, the majority of previous studies have focused on breast and prostate cancer patients and their married partners in Western countries [1], and many are limited by qualitative designs, with relatively small sample size. Therefore, a quantitative research that focuses on diverse relationships, larger sample size, and diverse ethnic backgrounds is necessary.

This study expands upon previous work by investigating the following research questions: (1) to what extent do patients and caregivers perceive their family to be avoidant of communication regarding cancer, and to what extent do these perceptions interrelate; (2) how do such perceptions influence their own and each other's communication behaviors, communication outcome, mental health, and quality of life.

\section{Materials and Methods}

\section{Study design and subjects}

This study was conducted as part of Cancer Patient Experience (CaPE) Study, which is an annual nationwide survey of cancer patient experience in Korea. In 2011, the study was conducted with patient-caregiver dyads, to explore medical care and treatment views of cancer patients and family caregivers. The National Cancer Center and the nine government-designated Regional Cancer Centers in Korea participated in the survey. The study was approved by the Institutional Review Board of the National Cancer Center, Korea.

Patients accompanied by family caregivers in outpatient waiting areas or inpatient wards were recruited for this study and provided explanations of the purpose and procedure of the survey. Inclusion criteria for patients were as follows: (1) over 18 years of age, (2) cancer diagnosis, (3) currently receiving cancer treatment or follow-up care, and (4) physically and mentally healthy to complete the study questionnaire. Inclusion criteria for caregivers were as follows: (1) an accompanying family member of a cancer patient and (2) over 18 years of age.

Patient-caregiver dyads were enrolled when both the patient and family member agreed to participate. We approached 1,299 dyads and enrolled a total of 990 (participation rate, $76.2 \%$ ) cases. Consenting patients and their family members were instructed to independently complete the questionnaires in a separate area to avoid influencing their answers. Medical baseline data, including primary cancer diagnosis, Surveillance, Epidemiology, and End Results (SEER) stage, and time since cancer diagnosis, were retrieved from hospital information systems at the participating centers.

\section{Measures}

To examine the dyadic interaction, we developed linked patient and family member questionnaires. Both patients and caregivers were administered with the Family Avoidance of Communication about Cancer (FACC), which was originally 
Table 1. Characteristics of the 990 dyads of patients and caregivers

\begin{tabular}{|c|c|c|}
\hline Characteristic & Patients $(n=990)$ & Caregivers $(\mathrm{n}=990)$ \\
\hline Age (mean \pm SD, yr) & $59.5 \pm 12.9$ & $50.0 \pm 14.5$ \\
\hline \multicolumn{3}{|l|}{ Sex } \\
\hline Male & $459(46.4)$ & $375(37.9)$ \\
\hline Female & $531(53.6)$ & $615(62.1)$ \\
\hline \multicolumn{3}{|l|}{ Marital status } \\
\hline Married & $820(82.8)$ & $793(80.1)$ \\
\hline Unmarried & $169(17.1)$ & $197(19.9)$ \\
\hline Missing & $1(0.1)$ & 0 \\
\hline \multicolumn{3}{|l|}{ Education } \\
\hline Less than high school (<9 yr) & $454(45.9)$ & $246(24.8)$ \\
\hline High school and above ( $\geq 9 \mathrm{yr}$ ) & $532(53.7)$ & $740(74.7)$ \\
\hline Missing & $4(0.4)$ & $4(0.4)$ \\
\hline \multicolumn{3}{|l|}{ Monthly income (KRW) } \\
\hline$<2$ million & $574(58.0)$ & $465(47.0)$ \\
\hline$\geq 2$ million & $406(41.0)$ & $520(52.5)$ \\
\hline Missing & $10(1.0)$ & $5(0.5)$ \\
\hline \multicolumn{3}{|l|}{ Cancer type } \\
\hline Stomach & $111(11.2)$ & - \\
\hline Lung and bronchus & $108(10.9)$ & - \\
\hline Liver & $47(4.7)$ & - \\
\hline Colorectal & $163(16.5)$ & - \\
\hline Breast & $226(22.8)$ & - \\
\hline Cervix and uterus & $58(5.9)$ & - \\
\hline Other & $277(28.0)$ & - \\
\hline \multicolumn{3}{|l|}{ SEER cancer stage (current) } \\
\hline In situ and local & $279(28.2)$ & - \\
\hline Regional & $295(29.8)$ & - \\
\hline Distant & $383(38.7)$ & - \\
\hline Unknown/missing & $33(3.3)$ & - \\
\hline Time since diagnosis (mean $\pm S D, y r)$ & $1.6 \pm 2.3$ & - \\
\hline$<1$ & $594(60.0)$ & - \\
\hline $1-5$ & $327(33.0)$ & - \\
\hline$>5$ & $69(7.0)$ & - \\
\hline \multicolumn{3}{|l|}{ Current treatment status } \\
\hline Under initial treatment & $562(56.8)$ & - \\
\hline On regular follow-up after treatment & $196(19.8)$ & - \\
\hline On regular follow-up after cure & $26(2.6)$ & - \\
\hline Under treatment for metastasis or Recurrence & $198(20.0)$ & - \\
\hline Not sure & $4(0.4)$ & - \\
\hline Other (e.g., treatment for second primary cancer) & $4(0.4)$ & - \\
\hline \multicolumn{3}{|l|}{ Relationship with patient } \\
\hline Spouse & - & $544(54.9)$ \\
\hline Son/daughter & - & $185(18.7)$ \\
\hline Son-/ daughter-in-law & - & $47(4.7)$ \\
\hline Parent & - & $146(14.7)$ \\
\hline Sibling & - & $42(4.2)$ \\
\hline Other & - & $14(1.4)$ \\
\hline Missing & - & $12(1.2)$ \\
\hline \multicolumn{3}{|l|}{ Living with patient } \\
\hline Yes & - & $737(74.4)$ \\
\hline No & - & $253(25.6)$ \\
\hline
\end{tabular}

Values are presented as number (\%) unless otherwise indicated. SD, standard deviation; SEER, Surveillance, Epidemiology, and End Results. 
Table 2. Perception of Family Avoidance of Communication about Cancer (FACC) between patients and their family caregivers

\begin{tabular}{|c|c|c|c|c|}
\hline \multirow{2}{*}{ FACC items (Cronbach $\alpha=0.88$ for patient; 0.92 for caregiver) } & \multirow{2}{*}{$\begin{array}{c}\text { Patient } \\
\text { response }\end{array}$} & \multirow{2}{*}{$\begin{array}{l}\text { Caregiver } \\
\text { response }\end{array}$} & \multicolumn{2}{|c|}{ Correlation between dyads } \\
\hline & & & Spearman's $\rho$ & p-value \\
\hline 1. Family members discourage me from talking about the cancer & $11.2 \pm 19.0$ & $15.6 \pm 20.1$ & 0.13 & $<0.001$ \\
\hline 2. In my family, the motto about cancer is 'don't ask, don't tell' & $9.0 \pm 16.7$ & $13.0 \pm 18.7$ & 0.16 & $<0.001$ \\
\hline 3. If I start talking about cancer, family members change the subject & $10.2 \pm 17.9$ & $15.1 \pm 19.5$ & 0.20 & $<0.001$ \\
\hline 4. Almost no one in my family will talk with me about the cancer & $12.1 \pm 20.5$ & $18.1 \pm 22.7$ & 0.19 & $<0.001$ \\
\hline 5. Family members get upset with me if I talk about cancer & $11.9 \pm 19.6$ & $15.7 \pm 20.1$ & 0.13 & $<0.001$ \\
\hline Mean score & $10.9 \pm 15.5$ & $15.5 \pm 17.5$ & 0.23 & $<0.001$ \\
\hline
\end{tabular}

Values are presented as mean \pm standard deviation or number. Higher score reflects higher levels of avoidance (range, $0-100$ ).

Table 3. Associations between patient- and caregiver-perceived family avoidance and their communication behavior

\begin{tabular}{|c|c|c|c|c|c|c|c|}
\hline \multirow{2}{*}{ Variable } & \multirow{2}{*}{$\begin{array}{l}\text { Descriptive } \\
\text { statistics }\end{array}$} & \multicolumn{3}{|c|}{ Patient-perceived FACC } & \multicolumn{3}{|c|}{ Caregiver-perceived FACC } \\
\hline & & Mean \pm SD & Spearman's $\boldsymbol{\rho}$ & p-value & Mean \pm SD & Spearman's $\rho$ & p-value \\
\hline \multicolumn{8}{|l|}{$\begin{array}{l}\text { Patient communication } \\
\text { behavior }\end{array}$} \\
\hline Disclosure (range, 1-5) & $3.7 \pm 1.3$ & - & -0.616 & $<0.001$ & - & -0.027 & 0.396 \\
\hline \multicolumn{8}{|l|}{ Holding back } \\
\hline Yes $(\%)$ & 4.4 & $1.91 \pm 0.93$ & - & $<0.001$ & $1.79 \pm 0.97$ & - & 0.134 \\
\hline No $(\%)$ & 95.6 & $1.40 \pm 0.59$ & - & & $1.62 \pm 0.69$ & - & \\
\hline \multicolumn{8}{|l|}{$\begin{array}{l}\text { Caregiver communication } \\
\text { behavior }\end{array}$} \\
\hline Disclosure (range, 1-5) & $3.3 \pm 1.2$ & - & -0.05 & 0.116 & - & -0.1506 & $<0.001$ \\
\hline \multicolumn{8}{|l|}{ Holding back } \\
\hline Yes $(\%)$ & 10.2 & $1.75 \pm 0.90$ & - & $<0.001$ & $1.99 \pm 0.86$ & - & $<0.001$ \\
\hline No $(\%)$ & 89.8 & $1.39 \pm 0.56$ & - & & $1.53 \pm 0.63$ & - & \\
\hline
\end{tabular}

FACC, Family Avoidance of Communication about Cancer; SD, standard deviation.

developed for patients with breast cancer [13]. We adapted the sentences to make it suitable for caregivers. The original authors of FACC suggested measuring both patient and caregiver perceptions of avoidance in order to determine the optimal focus for interventions [13]. The FACC scale is a single construct measure, and consists of five items that measure the individual's perception of the extent to which his/her family avoids talking about the cancer experience. Each item is measured on a 5-point Likert scale (1, less avoidance; 5 , more avoidance), and its score was transformed to range from 0 to 100 . The FACC score of individual patients is calculated as the mean score for each item. The Cronbach's alpha for the original version was 0.92 . The present data produced a similar internal consistency coefficient, 0.88 and 0.92 for patient and caregiver, respectively.

We also measured self-reported communication behavior of disclosure and holding back, each by a single item meas- ure $[4,15]$. Disclosure was measured by asking the respondent to answer the sentence, "I do honestly disclose my feelings, emotions, and thoughts about cancer to my family / the patient" on a 5-point Likert scale (1, never; 5, definitely). Holding back was probed by the following question: "Do you hide anything about your / the patient's status from your family/the patient?" This question was answered by a yes/no and scored dichotomously.

We used four outcome measures. The 18-item Cancer Communication Assessment Tool for Patients and Families (CCAT-PF) scale, which measures communication difficulty between patients and caregivers, was administered to examine communication outcomes [16]. The Hospital Anxiety and Depression Scale (HADS) was used to measure both patient and caregiver depression and anxiety. The European Organization on Research and Treatment on Cancer-Quality of Life Questionnaire core module (EORTC QLQ C30) and Care- 
Table 4. Summary statistics of outcome variables

\begin{tabular}{|c|c|c|c|c|c|}
\hline Outcome & Possible range & Minimum & Maximum & Mean & Standard deviation \\
\hline \multicolumn{6}{|l|}{ Cancer communication } \\
\hline CCAT-PF & $0-90$ & 1 & 60 & 23.7 & 8.7 \\
\hline \multicolumn{6}{|l|}{ Mental Health (HADS) } \\
\hline Patients' anxiety & $0-21$ & 0 & 21 & 6.0 & 4.2 \\
\hline Patients' depression & $0-21$ & 0 & 21 & 9.7 & 4.2 \\
\hline Caregivers' anxiety & $0-21$ & 0 & 21 & 6.6 & 4.3 \\
\hline Caregivers' depression & $0-21$ & 0 & 21 & 9.7 & 4.2 \\
\hline \multicolumn{6}{|l|}{ Quality of life } \\
\hline \multicolumn{6}{|c|}{ Patients' quality of life (EORTC QLQ C30) } \\
\hline Physical function & $0-100$ & 0 & 100 & 61.0 & 26.0 \\
\hline Role function & $0-100$ & 0 & 100 & 64.4 & 31.4 \\
\hline Emotional function & $0-100$ & 0 & 100 & 69.9 & 26.8 \\
\hline Cognitive function & $0-100$ & 0 & 100 & 70.2 & 26.4 \\
\hline Social function & $0-100$ & 0 & 100 & 65.0 & 29.2 \\
\hline Overall quality of life & $0-100$ & 0 & 100 & 54.1 & 22.4 \\
\hline \multicolumn{6}{|c|}{ Caregiver's quality of life (CQOL) } \\
\hline Burden & $0-40$ & 0 & 40 & 22.8 & 8.4 \\
\hline Positive adaptation & $0-28$ & 0 & 26 & 13.5 & 5.2 \\
\hline Disruptiveness & $0-28$ & 3 & 28 & 18.6 & 5.9 \\
\hline Financial concern & $0-12$ & 0 & 12 & 7.4 & 3.5 \\
\hline Total score ${ }^{\mathrm{a})}$ & $0-140$ & 17 & 130 & 81.4 & 20.0 \\
\hline
\end{tabular}

CCAT-PF, Cancer Communication Assessment Tool for Patients and Families; HADS, Hospital Anxiety and Depression Scale; EORTC QLQ 30, European Organization on Research and Treatment on Cancer-Quality of Life Questionnaire core module. a)Sum of individual CQOL domain is not 140 as not all 35 items load on a domain.

giver Quality of Life Scale were used to measure the quality of life of patients and caregivers, respectively.

\section{Statistical analyses}

Descriptive statistics for patient and family caregiver responses were obtained. The extent of concordance between patient- and caregiver-perceived FACC was determined by the Spearman's rho. Analyses were performed to examine the relationship between patient- and caregiver-perceived FACC and self-reported communication behavior, i.e., disclosure (by spearman correlation) and holding back (by independent $\mathrm{t}$ test).

A series of multivariable linear regression analyses were conducted to examine the influence of patient- and caregiverperceived FACC on communication, mental health, and quality of life. As the correlation between patient- and caregiver-perceived FACC was low (0.23), both were included in a multivariable model along with other covariates (both patient's and caregiver's age, sex, educational level, cancer stage, and caregivers' relationship to patients), which was selected based on both theoretical background $[17,18]$ and statistical associations with outcome variables in our data.
Assumptions for linear regression were tested by residual plots. All statistical analyses were conducted using the STATA ver. 12.0 (Stata Corp., College Station, TX), and p-values of $<0.05$ was considered statistically significant.

\section{Results}

\section{Baseline characteristics}

Table 1 shows the sociodemographic and health status characteristics of the 990 patient-family dyads. Patients' average age was 59.5 years and were slightly more likely to be female (53.6\%) than male. The majority of patients $(60 \%)$ had their diagnosis less than a year, and slightly more than half were in the initial treatment phase (56.8\%). Caregivers were somewhat younger, better educated, more likely to be female, and more financially secure. Slightly more than half of caregivers (54.9\%) were spouses, $18.7 \%$ were adult children, and $14.7 \%$ were parents of the patient. 
Table 5. Communication, mental health, and quality of life outcomes of family avoidance of communication about cancer

\begin{tabular}{|c|c|c|c|c|c|c|}
\hline \multirow{2}{*}{ Outcome } & \multicolumn{3}{|c|}{ Patient-perceived FACC } & \multicolumn{3}{|c|}{ Caregiver-perceived FACC } \\
\hline & Beta & SE & p-value & Beta & SE & p-value \\
\hline \multicolumn{7}{|l|}{ Cancer communication } \\
\hline CCAT-PF & 0.077 & 0.018 & $<0.001$ & 0.060 & 0.016 & $<0.001$ \\
\hline \multicolumn{7}{|l|}{ Mental Health (HADS) } \\
\hline Patients' anxiety & 0.077 & 0.009 & $<0.001$ & -0.001 & 0.008 & 0.849 \\
\hline Patients' depression & 0.062 & 0.009 & $<0.001$ & 0.013 & 0.008 & 0.094 \\
\hline Caregivers' anxiety & 0.024 & 0.009 & 0.005 & 0.040 & 0.008 & $<0.001$ \\
\hline Caregivers' depression & 0.013 & 0.008 & 0.116 & 0.050 & 0.007 & $<0.001$ \\
\hline \multicolumn{7}{|l|}{ Quality of life } \\
\hline \multicolumn{7}{|c|}{ Patients' quality of life (EORTC QLQ C30) } \\
\hline Physical function & -0.209 & 0.054 & $<0.001$ & 0.057 & 0.048 & 0.239 \\
\hline Role function & -0.295 & 0.065 & $<0.001$ & -0.050 & 0.058 & 0.388 \\
\hline Emotional function & -0.449 & 0.054 & $<0.001$ & 0.014 & 0.048 & 0.778 \\
\hline Cognitive function & -0.287 & 0.055 & $<0.001$ & 0.013 & 0.049 & 0.792 \\
\hline Social function & -0.372 & 0.059 & $<0.001$ & 0.000 & 0.053 & 0.999 \\
\hline Overall quality of life & -0.243 & 0.047 & $<0.001$ & 0.052 & 0.041 & 0.207 \\
\hline \multicolumn{7}{|c|}{ Caregiver's quality of life (CQOL) } \\
\hline Burden & -0.073 & 0.017 & $<0.001$ & -0.038 & 0.016 & 0.015 \\
\hline Positive adaptation & 0.027 & 0.011 & 0.011 & -0.052 & 0.010 & $<0.001$ \\
\hline Disruptiveness & -0.038 & 0.012 & 0.002 & -0.043 & 0.011 & $<0.001$ \\
\hline Financial concern & -0.028 & 0.007 & $<0.001$ & -0.009 & 0.006 & 0.160 \\
\hline Total score & -0.141 & 0.042 & 0.001 & -0.187 & 0.038 & $<0.001$ \\
\hline
\end{tabular}

Multivariable linear regression analyses were performed adjusting for patient's and caregiver's age, sex, educational level, cancer stage, and caregivers' relationship to patients. FACC, Family Avoidance of Communication about Cancer; SE, standard error; CCAT-PF, Cancer Communication Assessment Tool for Patients and Families; HADS, Hospital Anxiety and Depression Scale; EORTC QLQ 30, European Organization on Research and Treatment on Cancer-Quality of Life Questionnaire core module.

\section{Patient- and caregiver-perceived family avoidance of communication about cancer}

The mean scores of patient- and caregiver-perceived FACC were low at 10.9 and 15.5, respectively. However, the standard deviation was relatively high, with 15.5 and 17.5 on a 0-100 scale. Caregiver-perceived FACC was larger than that of patients ( $\mathrm{p}<0.001$, paired samples $\mathrm{t}$ test). Concordance between patient- and caregiver-perceived FACC was low with the Spearman's rho of 0.23 (Table 2).

\section{Associations with communication behavior}

Patient-perceived FACC was associated with lower levels of disclosure and holding back communication behavior of patients, and the same was true for caregivers (all $\mathrm{p}<0.001$ ). Patient-perceived FACC was associated with caregiver holding back ( $\mathrm{p}<0.001)$, but not with disclosure. Caregiverperceived FACC was not associated with patient's disclosure or holding back (Table 3).

\section{Influence on communication, mental health, and quality of life outcomes}

Summary statistics of outcome variables are presented in Table 4. In a multivariable analysis, both patient- and caregiver-perceived FACC were independently associated with communication difficulty as measured by CCAT-PF (both $\mathrm{p}$ $<0.001)$. Patient-perceived FACC was associated with all domains of patient's own mental health and quality of life, and the same was applied for caregiver-perceived FACC, except for financial concern domain. Patient-perceived FACC was significantly correlated with caregiver's depression level and all domains of caregiver quality of life (all $\mathrm{p}<0.05$ ). Caregiver-perceived FACC was not associated with patient mental health or most domains of quality of life, except for a non-significant but noteworthy association with patient depression $(\mathrm{p}=0.094)$ (Table 5). 


\section{Discussion}

Communication is a transactional process in which individuals create, share, and regulate meaning. Given that research on communication between cancer patient-caregiver dyads has been sparse to date, our data offers an advantage of investigating both patients and caregiver-perceived FACC simultaneously, and analyzing the mutual influence on patient and caregiver outcomes.

In general, contrary to our expectations, the level of perceived avoidance between patients and caregivers about cancer was found to be generally low. Unlike earlier studies performed in the 20th century [5-7], recent studies similarly showed relatively low prevalence of perceived family avoidance of communication [13] and consequently high levels of disclosure with one another [19]. However, there were wide variations between families in their reports of avoidance level, indicating that a minority of patients or caregivers acknowledged substantial communication difficulties [13]. The mean FACC scores were lower than those reported from the original validation study (10.9 vs. 13.2), in which the tool had been administered to patients with advanced lung cancer and their families [13]. This may be due to the inclusion of relatively healthy cancer patients and their caregivers in the present study. Specifically, family communication becomes tense as the disease progresses in severity [9]. Although we did not intentionally exclude terminally ill patients, most patients were recruited from ambulatory setting, and were often in treatment or follow-up. Another possible explanation could be cultural difference. In an Israeli study, caregivers born in Europe or America displayed significantly more communication difficulties with patients compared to those born in Israel and Asia/North Africa [10]. Individuals from non-Western cultures tend to be more family-oriented, and show emotional co-dependence and strong relationships between family members. Such cultural factors may have reduced avoidance behaviors in our sample.

Interestingly, caregivers' perceived level of communication avoidance was higher than that of patients. Similarly, in geriatric populations, it has been reported that caregivers experienced more difficulty in discussing patients' illness than the patients themselves $(37.3 \%$ vs. $22.3 \%$ for caregivers and patients, respectively) [20]. In a study of gastrointestinal cancer patients that investigated self-reported disclosure and holding back behavior, patients showed lower degree of disclosure (2.79 vs. 3.59, on 0-5 scale) and similar level of holding back regarding cancer-related concern (1.19 vs. 1.03) [15]. Caregivers often have more concerns regarding the patients' health status and feelings than the patient, and thereby avoid discussions with patients for this reason [5].
There was weak concordance between patients and caregivers in their perceptions of FACC. It seems to be quite natural that patients and caregivers frequently have different perceptions regarding the openness of communication within a given family. Bachner and Carmel [9] showed that caregivers' perceived level of open communication is explained mostly by the caregivers' own characteristics, such as optimism, self-efficacy, and their own fear of death and dying. This implies that the perceived level of avoidance may be influenced more by personal characteristics than actual communication. Similarly, in a geriatric study with 162 patient-caregiver dyads, an agreement with the statement about the perceived difficulty in talking about patient's illness was low, with a kappa value of 0.192 [20]. In a study of gastrointestinal cancer patients, correlation between patient and spouse were $0.25(\mathrm{p}=0.09)$ for disclosure and 0.26 $(p=0.08)$ for holding back [15]. This means that openness of family communication during cancer trajectory should be evaluated from the perspective of both patients and caregivers in order to better understand the dyadic interaction. Indeed, Mallinger et al. [13] suggested interventions to facilitate open communication in the event that both patients and caregivers perceive high avoidance and interventions to help the patient evaluate his or her expectation in the event that only the patient perceives high avoidance. However, optimal use of dyadic evaluation in interventions should be evaluated in future research.

For both patients and caregivers, self-perceived FACC was associated with their own non-disclosure and holding back communication behavior. This indicates that if one perceives an avoidant atmosphere within their family, they refrain from open communication. However, patient- and caregiverperceived FACC was not generally associated with each other's communication behavior, except for a significant association between patient-perceived FACC and caregiver holding back. In this case, it is likely that patient's caregiver is actually holding back some information regarding the patient's status, and the patient is likely to recognize it [21].

In our examination of the influence of perceived FACC on communication, both patient- and caregiver-perceived FACC were independently associated with communication difficulty, as measured by the CCAT-PF. This means that FACC perceived either by the patient or caregiver reflects communication problems within the family, and the health care professionals should view the family as a "unit of care" in their effort to improve family communication [1,22].

Both patient- and caregiver-perceived FACC was associated with their respective mental health and quality of life. This is not surprising and is in line with previous studies. Specifically, patient-perceived avoidance has been associated with patient low self-esteem, depression, and negatively associated with well-being [23,24]. Caregiver-perceived 
avoidance has been reported to be associated with caregiver's depression level [9], emotional exhaustion [9], and caregiver burden [20]. It is likely that mutual communication acts as an important facilitator of individual emotional adjustment [3] and early mutual recognition of the problem [8-10].

Patient-perceived FACC was significantly correlated with the caregiver depression level and quality of life. In addition, although non-significant, there was a nevertheless noteworthy correlation between caregiver-perceived FACC and patient depression. In other words, each party's perceived FACC affect other party's psychological health and quality of life suggesting the importance of an open communication between patients and their families regarding their thoughts about cancer [10]. While Porter et al. [15] concluded that there was only limited support for their hypotheses that patient disclosure would be positively associated with spousal adjustment, there were significant correlations between patient holding back and spouse level of avoidance of thought and reminders of patient's cancer, and between spouse disclosure and improved doctor-patient relationships. Further research is necessary to investigate the influence of patient and caregiver communication perception and behaviors on each other's adjustment and health outcomes.

Several limitations of the present study should be acknowledged. First, it is not possible to determine the causality from this cross-sectional study. However, it is likely that these associations are bidirectional in nature, as suggested in a previous study [15]. While it is possible that patients with fewer symptoms and better quality of life, and caregivers with lesser burden and better quality of life may feel less restricted in disclosing their thoughts and feelings related to their cancer experience, it is also plausible that such disclosure can increase intimacy in their relationship, and consequently aid in the adjustment process $[15,23]$. Second, like most prior research, we considered only one family member, perceived as the primary caregiver, as the subject of our research, and could not consider the interconnectedness between multiple family members [1].

\section{Conclusion}

Despite the limitations, our study imparts important implications for future development of dyadic models in cancer communication research and practice. Our findings suggest that future research would benefit from the measurement of perceived avoidance of cancer communication from both patients and caregivers to depict a more comprehensive understanding of the caregiver-patient dynamic. In addition, our findings suggest that openness to communication may be a key modifiable target for future family intervention aimed at improving mental health and quality of life for patients, caregivers, and family members. Opennessenhancing interventions at the family level that target both patients and caregivers are warranted to facilitate effective communication concerning the cancer process. Ultimately, this may prove beneficial for optimal outcomes and heightened well-being for both patients and their caregivers [25].

\section{Conflicts of Interest}

Conflict of interest relevant to this article was not reported.

\section{Acknowledgments}

We would like to thank all patients and caregivers who participated in our study, and the physicians and coworkers in the participating cancer centers for the recruitment of study participants. The following 10 Korean institutions (regional cancer centers) participated in this study and data collection (in alphabetical order): National Cancer Center (Goyang), Busan Regional Cancer Center, Chungbuk Regional Cancer Center, Daegu-Gyeongbuk Regional Cancer Center, Daejeon Regional Cancer Center, Gangwon Regional Cancer Center, Gyeongnam Regional Cancer Center, Jeju Regional Cancer Center, Jeonbuk Regional Cancer Center, and Jeonnam Regional Cancer Center.

This work was supported by a grant of the National R\&D Program for Cancer Control (No. 1210150). 


\section{References}

1. Harris J, Bowen DJ, Badr H, Hannon P, Hay J, Regan Sterba K. Family communication during the cancer experience. J Health Commun. 2009;14 Suppl 1:76-84.

2. Gotcher JM. The effects of family communication on psychosocial adjustment of cancer patients. J Appl Commun Res. 1993; 21:176-88.

3. Boehmer U, Clark JA. Communication about prostate cancer between men and their wives. J Fam Pract. 2001;50:226-31.

4. Kornblith AB, Regan MM, Kim Y, Greer G, Parker B, Bennett $S$, et al. Cancer-related communication between female patients and male partners scale: a pilot study. Psychooncology. 2006;15:780-94.

5. Lichtman RR, Taylor SE, Wood JV. Social support and marital adjustment after breast cancer. J Psychosoc Oncol. 1988;5: 47-74.

6. Gotcher JM. Well-adjusted and maladjusted cancer patients: an examination of communication variables. Health Commun. 1995;7:21-33.

7. Heinrich RL, Schag CC, Ganz PA. Living with cancer: the Cancer Inventory of Problem Situations. J Clin Psychol. 1984; 40:972-80.

8. Zhang AY, Siminoff LA. Silence and cancer: why do families and patients fail to communicate? Health Commun. 2003; 15:415-29.

9. Bachner YG, Carmel S. Open communication between caregivers and terminally ill cancer patients: the role of caregivers' characteristics and situational variables. Health Commun. 2009;24:524-31.

10. Bachner YG, Gesis Z, Davidov E, Carmel S. Caregivers' communication with patients about illness and death: initial validation of a scale. Omega (Westport). 2008;57:381-97.

11. Northouse PG, Northouse LL. Communication and cancer: issues confronting patients, health professionals, and family members. J Psychosoc Oncol. 1988;5:17-46.

12. Beach WA, Anderson JK. Communication and cancer? Part I: The noticeable absence of interactional research. J Psychosoc Oncol. 2003;21:1-23.

13. Mallinger JB, Griggs JJ, Shields CG. Family communication and mental health after breast cancer. Eur J Cancer Care (Engl). 2006;15:355-61.

14. Fletcher BS, Miaskowski C, Given B, Schumacher K. The cancer family caregiving experience: an updated and expanded conceptual model. Eur J Oncol Nurs. 2012;16:387-98.
15. Porter LS, Keefe FJ, Hurwitz H, Faber M. Disclosure between patients with gastrointestinal cancer and their spouses. Psychooncology. 2005;14:1030-42.

16. Siminoff LA, Zyzanski SJ, Rose JH, Zhang AY. The Cancer Communication Assessment Tool for Patients and Families (CCAT-PF): a new measure. Psychooncology. 2008;17:1216-24.

17. Shin DW, Cho J, Roter DL, Kim SY, Sohn SK, Yoon MS, et al. Preferences for and experiences of family involvement in cancer treatment decision-making: patient-caregiver dyads study. Psychooncology. 2013;22:2624-31.

18. Park B, Kim SY, Shin JY, Sanson-Fisher RW, Shin DW, Cho J, et al. Prevalence and predictors of anxiety and depression among family caregivers of cancer patients: a nationwide survey of patient-family caregiver dyads in Korea. Support Care Cancer. 2013;21:2799-807.

19. Manne S, Badr H, Zaider T, Nelson C, Kissane D. Cancerrelated communication, relationship intimacy, and psychological distress among couples coping with localized prostate cancer. J Cancer Surviv. 2010;4:74-85.

20. Fried TR, Bradley EH, O'Leary JR, Byers AL. Unmet desire for caregiver-patient communication and increased caregiver burden. J Am Geriatr Soc. 2005;53:59-65.

21. Yun YH, Kwon YC, Lee MK, Lee WJ, Jung KH, Do YR, et al. Experiences and attitudes of patients with terminal cancer and their family caregivers toward the disclosure of terminal illness. J Clin Oncol. 2010;28:1950-7.

22. Northouse LL, Mood DW, Schafenacker A, Kalemkerian G, Zalupski M, LoRusso P, et al. Randomized clinical trial of a brief and extensive dyadic intervention for advanced cancer patients and their family caregivers. Psychooncology. 2013;22: 555-63.

23. Cordova MJ, Cunningham LL, Carlson CR, Andrykowski MA. Social constraints, cognitive processing, and adjustment to breast cancer. J Consult Clin Psychol. 2001;69:706-11.

24. Mesters I, van den Borne H, McCormick L, Pruyn J, de Boer M, Imbos T. Openness to discuss cancer in the nuclear family: scale, development, and validation. Psychosom Med. 1997;59: 269-79.

25. Northouse LL, Mood DW, Schafenacker A, Montie JE, Sandler HM, Forman JD, et al. Randomized clinical trial of a family intervention for prostate cancer patients and their spouses. Cancer. 2007;110:2809-18. 